\title{
The British Journal for the History of Science
}

http://journals.cambridge.org/BJH

Additional services for The British Journal for the History of Science:

Email alerts: $\underline{\text { Click here }}$

Subscriptions: Click here

Commercial reprints: $\underline{\text { Click here }}$

Terms of use : $\underline{\text { Click here }}$

\section{BJHS}

Daniela Wuensch and Klaus P. Sommer (eds.), Ludwig Borchardt, Die altägyptische Zeitmessung. Reprint mit einer Einleitung von Daniela Wuensch: Was die alten Ägypter über Uhren und Zeitmessung wussten. Göttingen: Termessos Verlag, 2013. Pp. 189. ISBN 978-3938016-14-5. €36.80 (hardback).

Alexandra von Lieven

The British Journal for the History of Science / Volume 46 / Issue 04 / December 2013, pp 716 - 718 DOI: 10.1017/S000708741300071X, Published online: 13 November 2013

Link to this article: http://journals.cambridge.org/abstract S000708741300071X

How to cite this article:

Alexandra von Lieven (2013). The British Journal for the History of Science, 46, pp 716-718 doi:10.1017/S000708741300071X

Request Permissions : $\underline{\text { Click here }}$ 
ancient Greece and China, Lloyd's study is nonetheless broad in scope and argues for a similar breadth of mind.

Chapter 1 discusses the common trope of placing humanity between God or gods and animals, and the idea that we are defined by what we are not. Humans immediately appear to be occupying a stable ontological space; that is, however, instantly disrupted by disagreeing theories of what separates man from animals, and, indeed, from gods. Chapter 2 analyses the idea of error, and introduces the 'understanding' of the title. This chapter strongly denies the soundness of any assumption of universalism in our understanding of error, as well as related concepts such as truth.

Chapter 3 reassesses previous understandings of ancient philosophy and science, and claims that the latter should be judged by its aims rather than its results: to focus on the mistakes or errors made is misleading in a study of the human condition in other civilizations. Lloyd takes a detailed look at a broad range of the concerns and aims of ancient science, and, indeed, what variously constituted science in different cultures at different points in history. The categories of modern science are meaningless when applied to ancient attempts to understand the world, Lloyd argues, but important attempts they were nonetheless.

Chapter 4, 'Language and audiences', once again suggests that context is key. Considering the problems that arise when we do not know or understand the audience for whom texts are made, Lloyd examines the role of philosophers in their various cultures and questions how this knowledge influences our understanding of their words.

Lloyd offers some solutions and propositions for moving forward in the field in the final chapter, 'Philosophical implications'. Lloyd also explores the problems of language, long held in literary and cultural theory as restrictive even when the language is a native tongue. Lloyd's particular study of ancient language further complicates the dynamic of understanding, when submersion in dead languages can never be total, and the limitations of translation are made apparent. The tensions between the literal and the metaphoric, and the judgements we make when we divide these concepts, are deconstructed. However, the ability to learn new frameworks through which we assess our personal experience is proven, Lloyd argues, and this offers direction for further research in the field.

For the scholar of the history of science, Lloyd's study is an insightful and often philosophical examination of the nature of the human condition in ancient societies. It is the awareness and analysis of the field's problems, the conceptual systems that the scholar is often unaware of and even trapped by, that provides a persuasive argument for the text. As stated in the introduction, on the agenda are not only ancient cosmologies but also 'both our understanding of the world, and more particularly our understanding of other people, and how they have understood the world' (p. 1, original emphasis). In this book, Lloyd successfully disrupts notions of ultimate, crosscultural, truths about being human and understanding humanity.

JESSICA Evans

University of Salford

Daniela Wuensch and Klaus P. Sommer (eds.), Ludwig Borchardt, Die altägyptische Zeitmessung. Reprint mit einer Einleitung von Daniela Wuensch: Was die alten Ägypter über Uhren und Zeitmessung wussten. Göttingen: Termessos Verlag, 2013. Pp. 189. ISBN 978-3938016-14-5. $€ 36.80$ (hardback).

doi:10.1017/S000708741300071X

Sometimes, scholarly books are of such importance that they remain the main starting point for any serious study of the subject in question for decades. The book reprinted here is certainly a prime example of this. Published originally in 1920, Borchardt's treatise is still the only comprehensive major study of clocks and time-measuring devices in ancient Egypt. Of course, new material has come to light and there have been advances in understanding of the long-known. 
Yet no other work more complete in scope has been published to date. Therefore a reprint of the scarce original is without question more than welcome. Despite the fact that it is slightly reduced in size, the photographic plates are almost as good as the original ones.

The reprint is introduced by an essay on the Egyptians' knowledge of clocks and timekeeping by Daniela Wuensch, as well as a short biographical piece on Borchardt, and notes on the reprint and its original by Klaus P. Sommer. Most important for readers of this journal is of course the first one, as it tries to situate Borchardt's book within the study of ancient science, as well as to assess the position of the ancient Egyptians therein. In the first respect, Wuensch succeeds in placing the work in its context of the late nineteenth and early twentieth centuries. However, one would have wished also for a bibliography of advances in the more than ninety years since Borchardt. Unfortunately, this is not given, except for a selective mentioning of some of the most important studies. Here, a real opportunity has been missed.

In the second respect, Wuensch's agenda is clearly to show that the ancient Egyptians were much better scientists than is usually assumed (e.g. by Otto Neugebauer). While the present reviewer in general sympathizes much with this view, it nevertheless needs to be stated that the author does not do herself a service by the actual treatment of the material. On the one hand, it becomes obvious that she is not very familiar with the sources she quotes. For example, on p. 16 she writes that the text of the 'clock-maker' Amenemhet would be a papyrus, while on the next page it is correctly called a tomb inscription. In a similar vein, on p. 34 she speaks about the shadow-clock text 'auf dem Kenotaph (Gedenkstein) von Seti I'. Apart from the fact that a cenotaph is in general not simply a memorial stone, this one definitely is not - in fact, it is a huge temple building (also known as Osireion) and the inscription is on the ceiling of the last hall. There are a few more such blunders, also, in the part on the historical setting, where, for example, on p. 13, Egyptologists will learn to their astonishment that Rochemonteix and Chassinat translated (!) the texts from Edfu Temple (in fact, they edited them, there being no full translation to date).

Wuensch is not an Egyptologist, for which she is not to be blamed. Still, if an author writes on ancient Egypt, one would wish for a certain degree of correctness and familiarity with the subject. This is all the more relevant, as on the other hand she gives her own opinion of Egyptian science in quite a factual way. Sadly, again this does not stand up to scrutiny. Her main thesis is that the Egyptians did not write scientific books but put their knowledge on the ceilings of temples, because they wanted to keep these things secret and mysterious. Now it is absolutely true that the lack of papyri from libraries is the main obstacle to a correct assessment of ancient Egyptian science, but the reasons are completely different and utterly unintentional. The problem is simply that there are only few preserved settlement finds of papyri, because of the later use of the same settlements and because of the water table within the settlement zone next to the Nile. Most well-preserved papyri therefore are tomb finds and, for obvious reasons, they contain mostly funerary texts, not scientific treatises. The temple ceilings and similar material, to the contrary, were never intended as repositories of knowledge, they were just decorated with astronomical texts because the celestial phenomena were also gods and vice versa. It was never intended that one would try to read the texts from a ceiling over fifteen metres above, when the same text was conveniently lying in the library. It is just our plight as modern scholars that we have to piece together the little that is preserved from any source we can get our hands and eyes on, something which the Egyptians could and would never have foreseen.

On p. 32 the author rightly states that the early Greek scientists learned from the Egyptians from the seventh century BCE. Yet I cannot follow her when she says that Egyptian science had at that period already long passed its culmination ('schon lange ihren Höhepunkt überschritten hatte'). I cannot see any reason for such an assumption. There are still many Egyptian scientific texts attested until the Roman period; it is only that, somehow, after 1000 BCE scholars tend to 
attribute any quality scientific material automatically to foreign influence. Even if true, that influence fell at least on fertile ground.

Speaking of such influence, though, it needs to be admitted that the Egyptians traditionally only had a 365-day year, not 365.25 as Wuensch claims on pp. 27 and 46. The leap year was only introduced in 238 BCE under Ptolemy III.

Be that as it may, one does not read a reprint for its introduction. As stated above, Borchardt's book is still the indispensable standard publication on ancient Egyptian clocks, therefore this book as a whole is heartily to be recommended.

AleXANDRA VON LIEVEN Freie Universität Berlin

Peter Elmer, The Miraculous Conformist: Valentine Greatrakes, the Body Politic, and the Politics of Healing in Restoration Britain. Oxford: Oxford University Press, 2013. Pp. xiii +279. ISBN 978-0-19-966396-5. £65.00 (hardback). doi:10.1017/S0007087413000721

Although a minor figure, Valentine Greatrakes, the Anglo-Irish faith healer, is a familiar figure to historians of science specializing in the Restoration period. Feted in his own day by contemporaries who saw the opportunity to use him as a perfect exemplar, or even embodiment, of their own religious and political aims, he has been used by recent historians to support their own claims about the nature of life and times in the Restoration. But just as Greatrakes was a controversial figure in his own day-not everybody saw him as a symbol of, much less a force for, moral regeneration-historians have interpreted his significance in differing ways. Here, in what will surely come to be seen as the definitive treatment of 'the Irish stroker', Peter Elmer now offers a highly judicious account based on meticulous scholarship. Resisting the temptation to jump to unsubstantiated conclusions, Elmer's account is always careful and well balanced, and offers an analysis which is nuanced and entirely persuasive.

Greatrakes has achieved a place in recent historiography of science thanks to the interest shown in him by Robert Boyle, and other more peripheral thinkers associated with the 'new philosophy', such as the Cambridge Platonist Henry More, and minor members of the Royal Society, such as John Beale and Joseph Glanvill. But Elmer's book is by no means focused entirely on this aspect of Greatrakes's brief period of fame in the early months of 1666 . Indeed, readers of this journal might be disappointed that Elmer does not provide a systematic reassessment of the ways in which participants in the new philosophies reacted to this seemingly successful wonder-worker. We learn that Robert Boyle remained sceptical of Greatrakes, but there is no real attempt to explain Boyle's response. But, given that one of the best sections in the book (pp. 143-153) is concerned with the minor virtuoso John Beale, and his attitude to Greatrakes, it may simply be that comparable historical evidence to judge Boyle's position does not exist. Certainly Boyle was far more circumspect about exploiting Greatrakes's supposed abilities for his own religious ends than was Henry More, who never let an opportunity to show the inadequacy of the mechanical philosophy, however dubious, pass him by.

Readers of this journal may also regret that Elmer did not spend more time discussing the reactions of physicians to this layman achieving cures where they could not. He tells us that Greatrakes won many testimonials from physicians, but the majority seem to have been reformist physicians who advocated the new chemical medicine against traditional Galenism. It is easy to see in general terms why this might have been, but there is no specific discussion of individual physicians, or even a wider discussion of how Greatrakes might have been used in debates about medicine as a profession. But again, this may simply be due to lack of evidence. Certainly, Elmer tells us of an attack on Greatrakes by an anonymous orthodox physician, but he cannot go into details because the pamphlet in question is 'sadly no longer extant' (p. 83). We are told that 